\title{
Flow Cytometry-Based Analysis and Sorting of Lung Dendritic Cells
}

\author{
Svetlana P. Chapoval \\ University of Maryland \\ USA
}

\section{Introduction}

Dendritic cells (DC) are very specialized antigen presenting cells which play critical roles in innate and adaptive immunity and in tolerance. Their major functions are to sample antigens throughout the body and to stimulate or tolerize T cells. DC consist of several distinct subsets with different tissue distribution, surface markers, and function. This chapter discusses the lung DC subsets, their specific array of distinguishing markers, various aspects of their biology and function based on the flow cytometry-derived studies for their isolation and characterization.

\section{Lung DC subpopulations}

Lung DC are sentinel cells originated in the bone marrow and through the peripheral circulation are constantly recruited to the lung tissue. They sense and capture antigens, and transport processed antigens to the draining lymph nodes where they interact with $\mathrm{T}$ cells. However, since lung DC form a heterogeneous sentinel cell population with distinct cell subtypes having different functions in the immune response, it is important to properly define these populations in order to use/stimulate the selected one(s) for a proper immune response regulation and/or protection from the disease.

\subsection{Discovery of DC}

DC were co-discovered in 1973 by Ralf M. Steinman and Zanvil A. Cohn at the Rockefeller University as a population of mouse spleen cells with unusual stellate morphology (Steinman \& Cohn, 1973). For this fundamental discovery Ralf M. Steinman was awarded the 2011 Nobel Prize in Physiology and Medicine. The first dendritic cell in skin with a typical dendritic morphology was described in 1868 by Paul Langerhans but, due to it morphology, was mistaken for a neuronal cell (Langerhans, 1898) and later was termed a Langerhans cell. In their seminal article defining DC as a novel cell population, Steinman and Cohn noted that DC constantly extend and retract many cell processes and have many different branches present at given time point, adhere to plastic and do not display an endocytic capacity of macrophages. The other feature that distinct these two adherent cell populations is the presence of many perinuclear acid phosphatise-positive granules in the cytoplasm of macrophages, whereas DC display only few tiny granules in this area. At that 
time, the scientists were able to localize DC presence only in lymphoid organs (spleen, lymph nodes, and Payer's patches) but not in other tissues studied such as thymus, liver, peritoneal cavity, intestine, and bone marrow. The presence of DC in the connective tissues of all organs including lungs was discovered a few years later (Kawanami, Basset, Ferrans, Soler, \& Crystal, 1981; Spencer \& Fabre, 1990; Steiniger, Klempnauer, \& Wonigeit, 1984). Lung DC are critical in controlling the immune response to inhaled antigen (K. Vermaelen \& Pauwels, 2005).

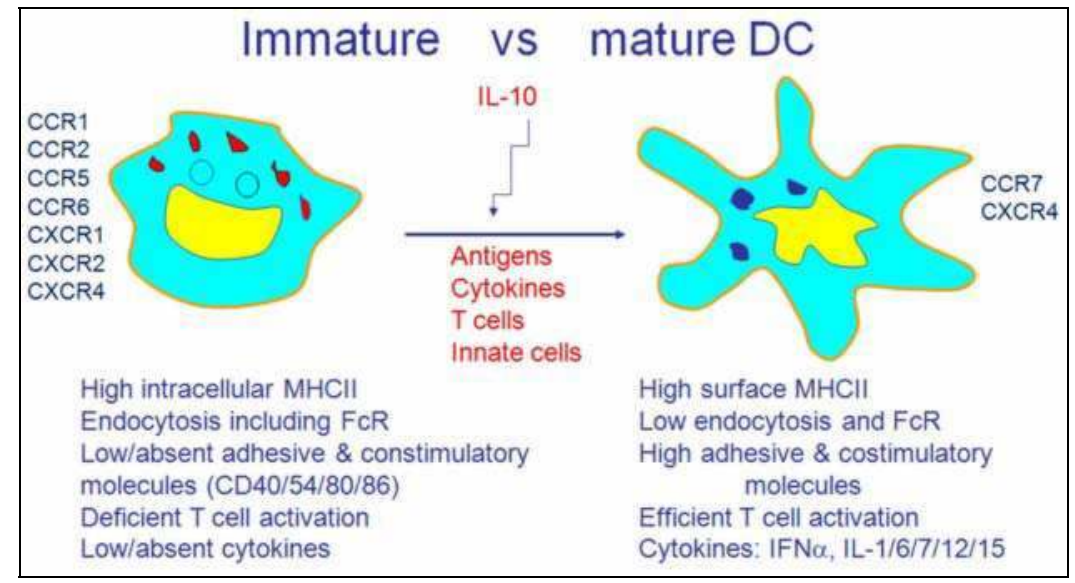

Fig. 1. Immature versus mature lung DC

Hematopoietic cell progenitor gives a rise to DC which populate the lung tissue in the immature state attracted by the specific chemokines and other mediators (K. Vermaelen \& Pauwels, 2005). Immature DC display a specific set of chemokine receptors, high endocytic ability, and low $\mathrm{T}$ cell stimulation activity. After antigen uptake and maturation, DC upregulate adhesion and costimulatory molecule expression and cytokine production but shut down the antigen-capturing activity and limit chemokine receptor expression.

\subsection{DC in the lung}

DC are present in the lung tissue in an immature state (Figure 1) what means they can perform a typical function for immature DC - recognise and sample antigens but cannot stimulate $\mathrm{T}$ cells. The normal tissue condition without any Ag-(or other factors) induced disturbance is defined as a steady state condition. In a steady state condition, immature DC are distributed throughout the lung tissue. Depending on their lung anatomical localization site, they were originally subdivided on airway subepithelial, lung parenchymal, and visceral pleura DC (Sertl et al., 1986). However, a more common classification of lung DC in a steady state condition subdivides them on three major classes based on the cell surface marker's expression and function: conventional (c)DC, plasmacytoid (p)DC, and alveolar DC (Lambrecht \& Hammad, 2009a, 2009b). DC constantly sample inhaled Ag and then mature and migrate to the $\mathrm{T}$ cell areas of the local lymphoid tissues, peribronchial (mediastinal) lymph nodes. Depending on many factors, including the nature and dose of $\mathrm{Ag}$, the cytokine milieu at the site of Ag entry, lung DC can either stimulate a clonal expansion of Ag-specific T cells (Figure 2) or induce tolerance. 


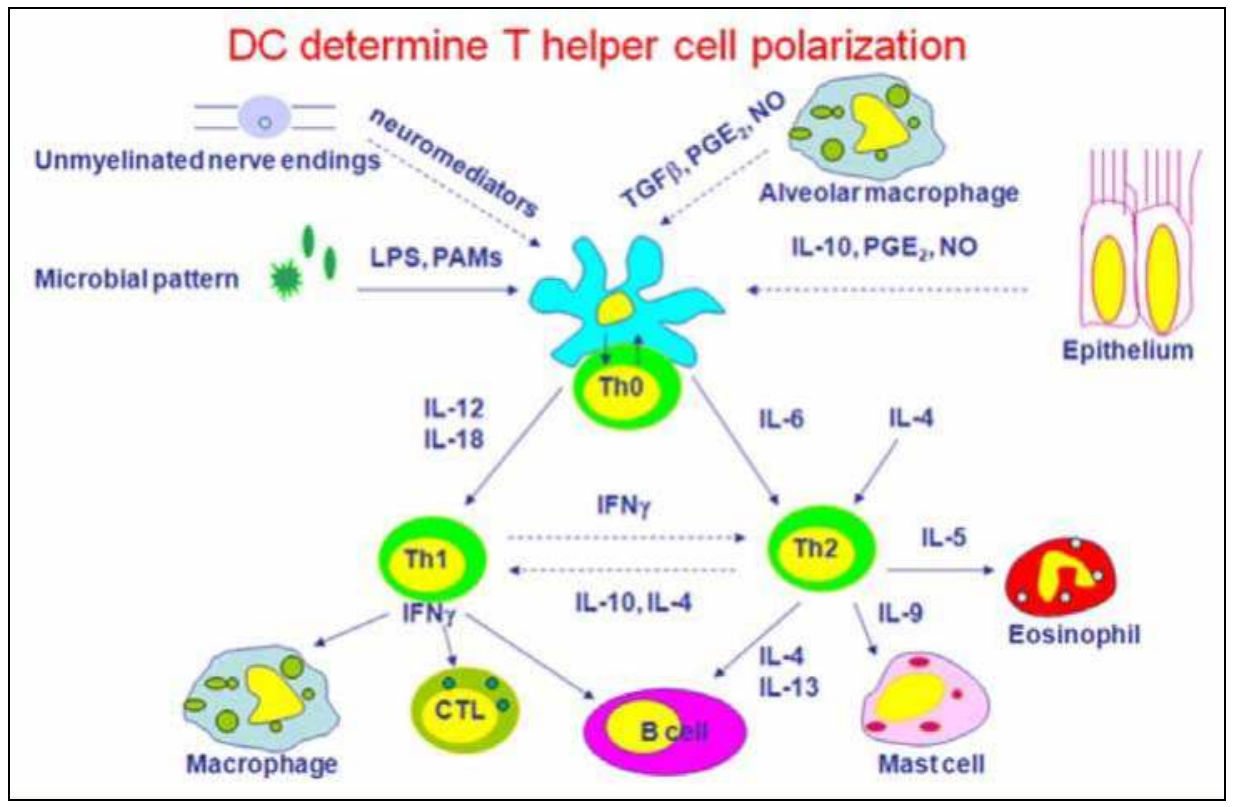

Fig. 2. DC determine Th cell polarization

DC maturation by inhaled antigen leads to their production of different cytokines which determine what type of helper T cell response will dominate, Th1 or Th2. Following DCinduced activation, generated Th cells produce a characteristic cytokine set which, in its turn, performs different functions acting on other cells involved in the response to the corresponding Ag. To avoid the potential harmful consequences of continuous lung DC activation, the cells are being kept in the immature state by different mechanisms involving products of unmyelinated nerve endings, alveolar macrophages, and airway epithelium.

The key role of DC in the interface between tolerance and immune response in the lung is a subject of many investigations (K. Vermaelen \& Pauwels, 2005). Currently, two major lung DC subpopulations are defined as $\mathrm{CDC}$ and $\mathrm{pDC}$ whereas alveolar DC are not well characterized (Chapoval et al., 2009; de Heer et al., 2004; Masten et al., 2006; Ritz et al., 2004). In addition to those two well characterized DC populations, more DC subtypes can exist under inflammatory conditions (Swanson et al., 2004). As these DC differ functionally, it is important to properly subdivide and characterize them for a further definition of their role in different pathologic conditions as well as for their potential use for a DC-based therapy of different diseases. Flow cytometry provides an important, reliable, and precise tool to separate and analyse different cells based on their specific phenotypic properties. Multicolor flow cytometry allows the use of multiple parameters simultaneously which helps to clearly define DC subpopulations and status.

\subsubsection{Isolation of lung cells for flow cytometric analysis}

To prepare the lung cells for a flow cytometry analysis, the lungs first were perfused with $20 \mathrm{ml}$ PBS via right ventricle, dissected from the thorax, and cut into small pieces using 
sterile surgical blades (VWR). We prepared single cell suspensions of lung cells in flow cytometry staining buffer consisting of 10\% FBS supplemented PBS ( free of divalent cations $\mathrm{Ca}^{2+}$ and $\mathrm{Mg}^{2+}$ ) with $0.01 \%$ of sodium azide. We used two different techniques for DC isolation. In a first technique, the single cell suspensions from the mouse lungs were prepared by mincing the organs into small pieces and digesting them with type IV collagenase (Worthington Biochemical) and DNAse (Roche) for $30 \mathrm{~min}$ at $37^{\circ} \mathrm{C}$ as described previously (Chapoval et al., 2009; Niu et al., 2007). For cell dissociation, digested cell suspensions were passed through a wire mesh and then through a $100 \mu \mathrm{m}$ nylon cell strainer (BD Falcon). RBC were lyzed with Ammonium-Chloride-Potassium (K) (chloride), ACK lysis buffer (Invitrogen).

In a second technique, the digestion step was omitted and the lung single cell suspensions were freshly prepared according to a procedure reported by Piggott DA et al. (Piggott et al., 2005). Briefly, lungs were physically disrupted by pushing the tissue between two sterile glass microscope slides (Thermoscientific). Then obtained cell suspensions were passed through cell strainers to remove the tissue debris and subjected to centrifugation over the Ficoll gradient to purify a leukocyte population from the contaminating cells. RBC lysis step was excluded when using this technique as RBC (together with neutrophils and eosinophils) aggregate at the bottom of a tube whereas leukocytes remain in the cell suspension-Ficoll interface.

Similarly, human lung cells were isolated from the surgically removed lung tissues distant from a primary resected lung carcinomas by cutting tissues into pieces followed by a type IA collagenase (Sigma) enzymatic digest for $1 \mathrm{~h}$ at $37^{\circ} \mathrm{C}$ (Cochand, Isler, Songeon, \& Nicod, 1999). The enzyme-digested tissue fragments were pushed through a stainless-steel screen and separated on a Ficoll-Paque density gradient to obtain pulmonary mononuclear cells. Cells were cultured in P10 Petri dishes in complete medium. The nonadherent cells were removed after $1 \mathrm{~h}$, using three rinses of Hanks' balanced salt solution without $\mathrm{Ca}^{2+}$ and $\mathrm{Mg}^{2+}$ (HBSS). The adherent cells were incubated for an additional $16 \mathrm{~h}$ period at $370 \mathrm{C}$ in complete medium. The cells released after three rinses of HBSS are referred to as loosely adherent mononuclear cell population.

DC can also be detected in the bronchoalveolar lavage (BAL) in mice (Fainaru et al., 2005; Jakubzick, Tacke, et al., 2008) and humans (van Haarst et al., 1994; Tsoumakidou et al., 2006). For BAL withdrawal in mice, airways were flushed three to four times with $1 \mathrm{ml}$ of sterile endotoxin-free PBS (Chapoval et al., 1999) or 0.5 mM EDTA/HBSS (Jakubzick, Tacke, et al., 2008) using a sterile $1 \mathrm{ml}$ syringe (Becton Dickinson) connected to either the blunt needle (Chapoval et al., 1999) or veterinary i.v. catheter (Chapoval et al., 2008). BAL cells were washed once with PBS or EDTA/HBSS by centrifugation. The cell pellets were resuspended in $1 \mathrm{~mL}$ of a corresponding buffer. Total leukocytes in BAL fluids were determined for each sample with a standard hemocytometer. For FACS analysis, BAL cells were resuspended in FACS blocking solution and stained for $30 \mathrm{~min}$ with appropriate conjugated Abs. BAL withdrawal in humans was performed with a flexible bronchoscope placed in the wedge position in the right middle lobe (van Haarst et al., 1994). Four aliquots of $50 \mathrm{ml}$ saline were subsequently instilled and aspirated. BAL fluid was collected in siliconized bottles. BAL cells were kept at $4^{\circ} \mathrm{C}$, washed twice in PBS containing $0.5 \%$ bovine serum albumin and $0.45 \%$ glucose, and subsequently filtered through a $55 \mu \mathrm{m}$ and a $30 \mu \mathrm{m}$ gauze. Human BAL DC selected as low autofluorescent cells were HLA-DR, L25, RFD1, and 
CD68 (van Haarst et al., 1994). A portion of these cells expressed CD1a (22\%) and My4 $(60 \%)$. The high autofluorescent cell fraction represented alveolar macrophages which were strongly positive for APh, HLA-DR, CD68, RFD7, and RFD9.

\subsubsection{Complex DC analysis using multicolor flow cytometry}

Multicolor flow cytometry is a unique, useful, and powerful analytical method to identify DC subpopulations in the lung among many lung resident and inflammatory cells, to define their activation and maturation stages, to identify their surface marker expression and, therefore, to extrapolate their role in the specific lung conditions.

In our work we used the following mAbs obtained from BD Biosciences Pharmingen in multicolor flow cytometry for lung DC subpopulation detection and characterization: antiI-A $\square$ b-biotin (AF6-120.1), anti-CD8 $\square$-PE (53-6.7), anti-CD11b- allophycocyanin-cyanin dye, APC-Cy7 (M1/70), anti-CD11c-FITC or -APC (HL3), anti-B220/CD45R-PE (RA3-6B2), antiGR1-FITC or -APC (Ly-6G and Ly-6C). PE-Cy-5-labeled Mac1 (CD11b/CD18) Ab that were used in some experiments were obtained from Cedarlane Laboratories. DEC-205 was visualized using rat anti-mouse CD205 Ab (NLDC-145) and STAR69 (F(ab')2 goat anti-rat IgG-FITC), both from Serotec (Oxford, UK). Biotinylated rat anti-mouse F4/80 Ab (CI:A3-1; Serotec) were used in combination with SAV-FITC (BD Pharmingen) for visualization of this macrophage marker. Streptavidin-peridinin chlorophyll protein, SAV-PerCP was used as a second step reagent for biotinylated anti-I-A $\square$ b. Where necessary, cells were preincubated with anti-CD16/CD32 (2.4G2) mAb for blocking cell surface FcR. Cells gated by forward- and side-scatter parameters were analyzed on either FACSCalibur or LSRII (Becton Dickinson) flow cytometer using either CELLQuest, FACSDiva, or FlowJo softwares.

\subsubsection{Lung conventional DC}

Proper flow cytometry-based characterization of lung DC is a complex issue as, in contrast to other organs, CD11c in the lung is expessed on DC and on a subset of lung macrophages (Jakubzick, Tacke, et al., 2008). Therefore, CD11c integrin with still undefined function (Lindquist et al., 2004; Metlay et al., 1990) can not serve as one definitive marker for lung DC. However, both cell types in the lung differ in the levels of autofluorescence (Jakubzick, Tacke, et al., 2008; Kirby, Raynes, \& Kaye, 2006; K. Y. Vermaelen, Carro-Muino, Lambrecht, \& Pauwels, 2001), MHC Class II expression (Jakubzick, Tacke, et al., 2008), and costimulatory molecule expression (Chelen et al., 1995).

Conventional DC are characterized as CD11c+MHCIIlowCD11b+ cells and $\mathrm{CD} 1 \mathrm{c}+\mathrm{CD} 11 \mathrm{c}+\mathrm{CD} 14-\mathrm{HLA}-\mathrm{DR}+$ cells in mice and human, correspondingly (Chapoval et al., 2009; de Heer et al., 2004; Masten et al., 2006; Ritz et al., 2004). In mice, cDC consist more than $95 \%$ of total lung DC in a steady state condition (Maraskovsky et al., 1996; Swanson et al., 2004; K. Vermaelen \& Pauwels, 2004). Lung cDC discrimination starts from elimination of autofluorescent cells based on dot plots of CD11c-empty channel (Figure 3). CD11b, an additional marker for $\mathrm{CDC}$, has other alternative names: ITGAM, integrin alpha M; Mac-1, macrophage-1, consists of CD11b plus CD18; complement receptor 3, CR3 (CD11b/CD18). CD11b in complex with CD18 mediates macrophage adhesion and migration (Solovjov, Pluskota, \& Plow, 2005). 


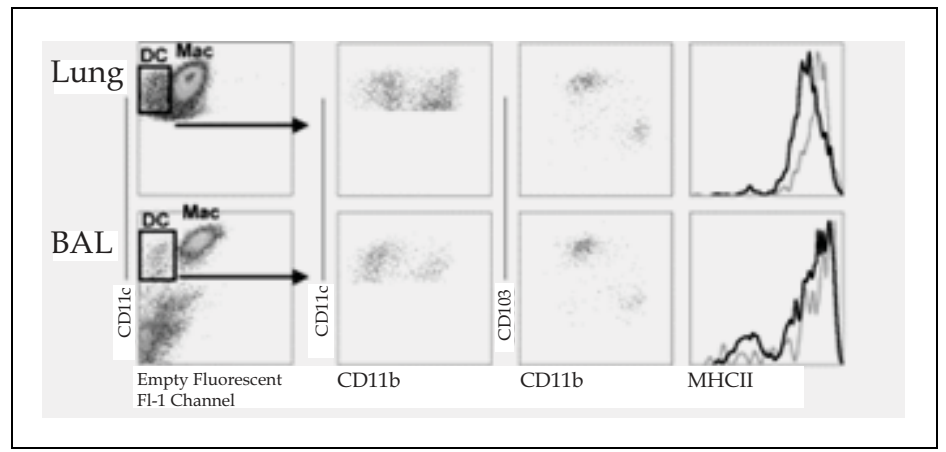

Fig. 3. Flow cytometry discrimination of lung $\mathrm{cDC}$

We studied the effect of lung epithelial cell-targeted expression of vascular endothelial growth factor (VEGF) on lung DC number and activation stage. We generated these mice in order to define the role of VEGF in allergic asthma as the exaggerated levels of lung VEGF were found in asthmatic persons (Lee et al., 2004). It has been shown previously that VEGF overexpression during lung development causes a fetal death (Zheng et al., 1998). We used a dual-construct transgenic system that can be regulated externally (Ray et al., 1997). This system is based on the production of animals with two transgenic constructs. The first, CC10-rtTA construct contained the CC10 (Clara Cell 10) promoter, the rtTA (a fusion protein made up of a mutated tetracycline repressor and the herpes virus VP-16 transactivator) and human growth hormone (hGH) intronic, with its nuclear localization sequence and polyadenylation sequences. The second, tet-O-CMV-hVEGF construct contained a polymeric tetracycline operator (tet-O), minimal cytomegalovirus (CMV) promoter, human $\mathrm{VEGF}_{165} \mathrm{CDNA}$, and $\mathrm{hGH}$ intronic and polyadenylation signals. In this system the CC10 promoter direct $\mathrm{s}$ the expression of rtTA to the lung. In the presence of doxycycline (Dox), rtTA is able to bind in trans to the tet-O, and the VP-16 transactivator activates VEGF gene transcription. In the absence of Dox, rtTA binding does not occur and transgene transcription is not activated.

We have found previously that lung VEGF expression induces local DC activation (Lee et al., 2004). In our research we performed the discriminatory analysis of lung cDC in WT and VEGF tg mice using different techniques (Figures 4 and 5). In Figure 4, we show that the population of cells that are considered to be macrophages with autofluorescence on empty channel (flow 6 in this study) contains both macrophages and cDC (this was supported by a Giemsa stain of sorted cytospinned cells (Chapoval et al., 2009)). Only a proper elimination of large highly autofluorescent cells on a FCS-SSC dot plot can help to distinguish these two cell populations in the whole lung cell suspension. Moreover, if lung cDC in Fig. 3 are MHCII high, we have notices that WT mouse lung CDC are MHCIIlow (Bhandari et al., 2006; Chapoval et al., 2009; Lee et al., 2004) what makes sense considering the steady state condition of the WT mouse lung in the absence of any treatment/exposure. However, it is important to note that the procedures used for the lung DC characterization by flow cytometry (enzymatic tissue digestion, centrifugations, incubation with Ab, etc.) will all lead to the modification of the lung DC original state (K. Vermaelen \& Pauwels, 2005) and, thus, different techniques, reagents used, procedure timing will impact the further cell discrimination by flow cytometry. 


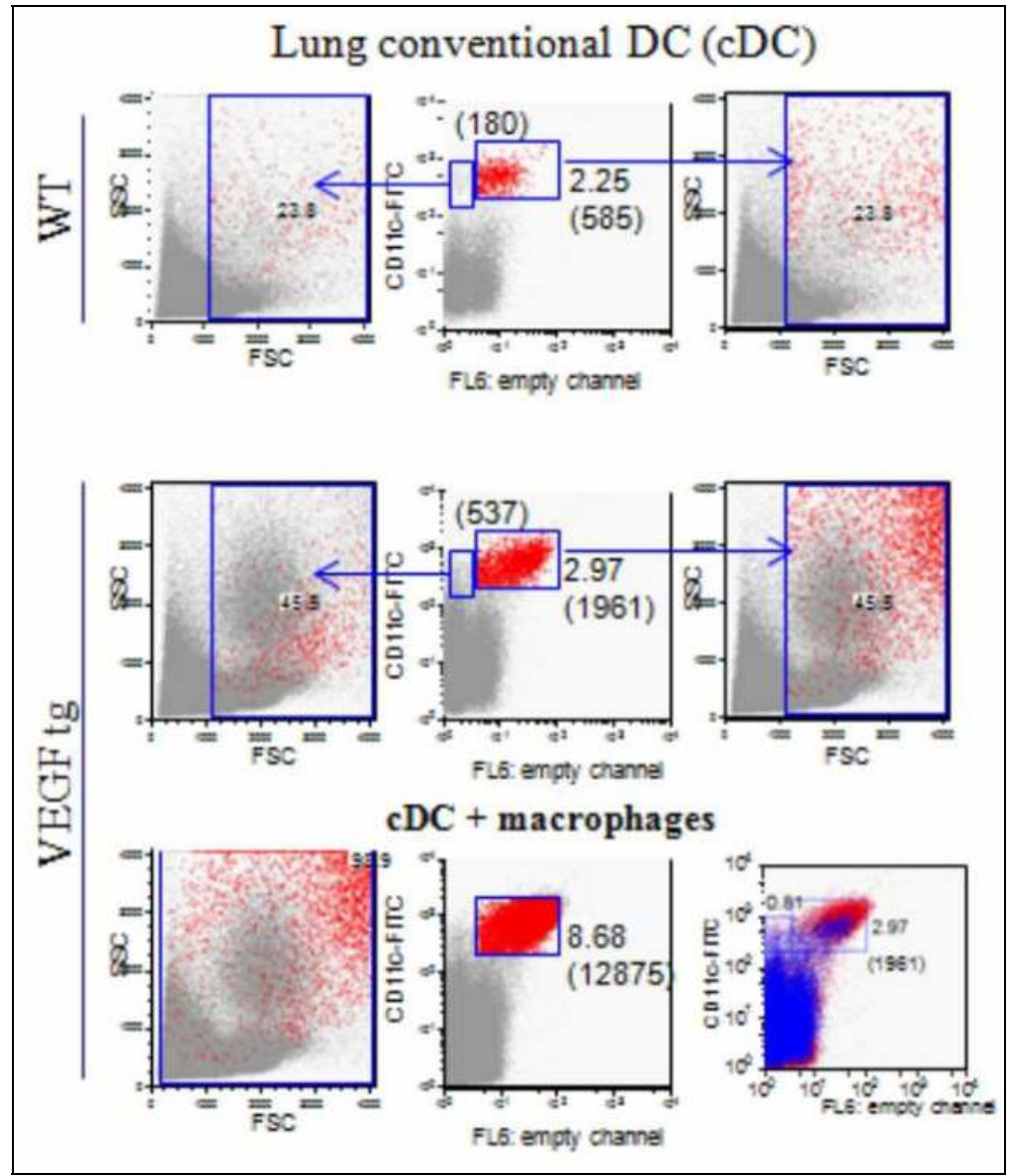

Fig. 4. Lung cDC gating strategy

The other discrimination technique was based on the assumption that $\mathrm{CD} 11 \mathrm{c}^{+} / \mathrm{high}$ autofluorescent lung cells do not express MHCII and, therefore, are alveolar macrophages, whereas cDC are CD11c+MHCII+ (K. Vermaelen \& Pauwels, 2004). This observation contrasts with the results obtained by us and others (Beaty, Rose, \& Sung, 2007; Chapoval et al., 2009; Sung et al., 2006) (Figure 5). As it can be seen in Fig. 5, the levels of MHCII expression on macrophages and $\mathrm{cDC}$ are the same.

Flow cytometry of whole lung cell suspension gated on CD11c+ cells, or BAL gated on live cells, stained for CD11c vs empty FITC fluorescent channel. High autofluorescent cells are defined as macrophages (Mac), whereas low autofluorescent cells are defined as DC. The flow cytometry plots in the center show the gated DC population stained for CD11c vs CD11b or CD103 vs CD11b. On the right, the histogram plots show that both DC subsets in the lung and in BAL, CD11blow DC (black line) and CD11chigh DC (grey line), express high levels of MHCII. Of note, this figure was provided by the Journal of Immunology as a onetime reproduction (Copyright 2008, the American Association of Immunologists, Inc.). 
The other discrimination technique was based on the assumption that $\mathrm{CD} 11 \mathrm{c}+/$ high autofluorescent lung cells do not express MHCII and, therefore, are alveolar macrophages, whereas cDC are CD11c+MHCII+ (K. Vermaelen \& Pauwels, 2004). This observation contrasts with the results obtained by us and others (Beaty, Rose, \& Sung, 2007; Chapoval et al., 2009; Sung et al., 2006) (Figure 5). As it can be seen in Fig. 5, the levels of MHCII expression on macrophages and $\mathrm{CDC}$ are the same.

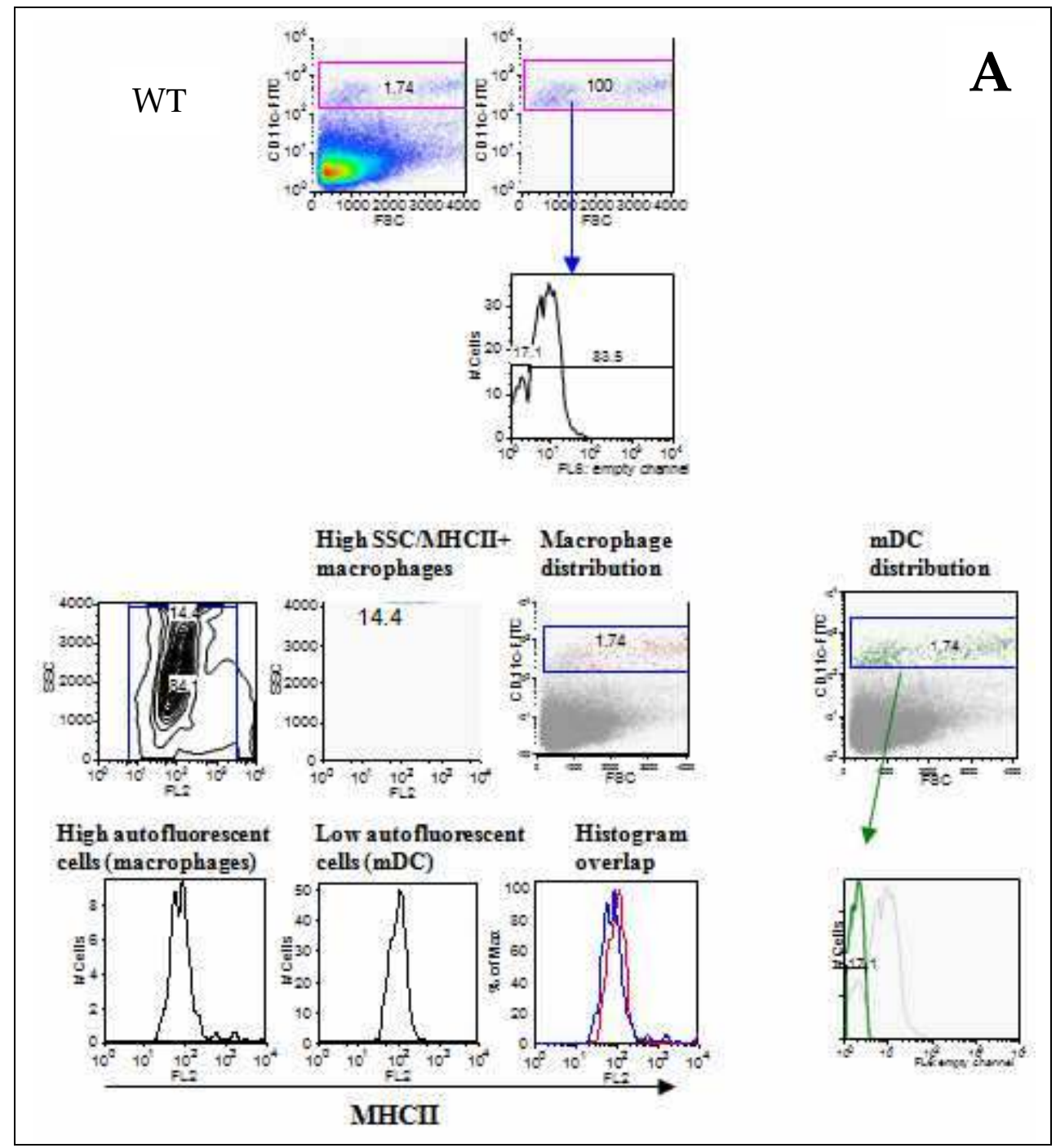

Fig. 5. (continues on next page) Application of flow cytometry gating strategies used by Vermealen K and Pauwels R (Vermaelen and Pauwels 2004) and Beaty SR and associates (Sung, Fu et al. 2006; Beaty, Rose et al. 2007) for a detailed analysis of WT (panel A) and VEGF tg (panel B) lung cDC (marked as myeloid, mDC) populations 


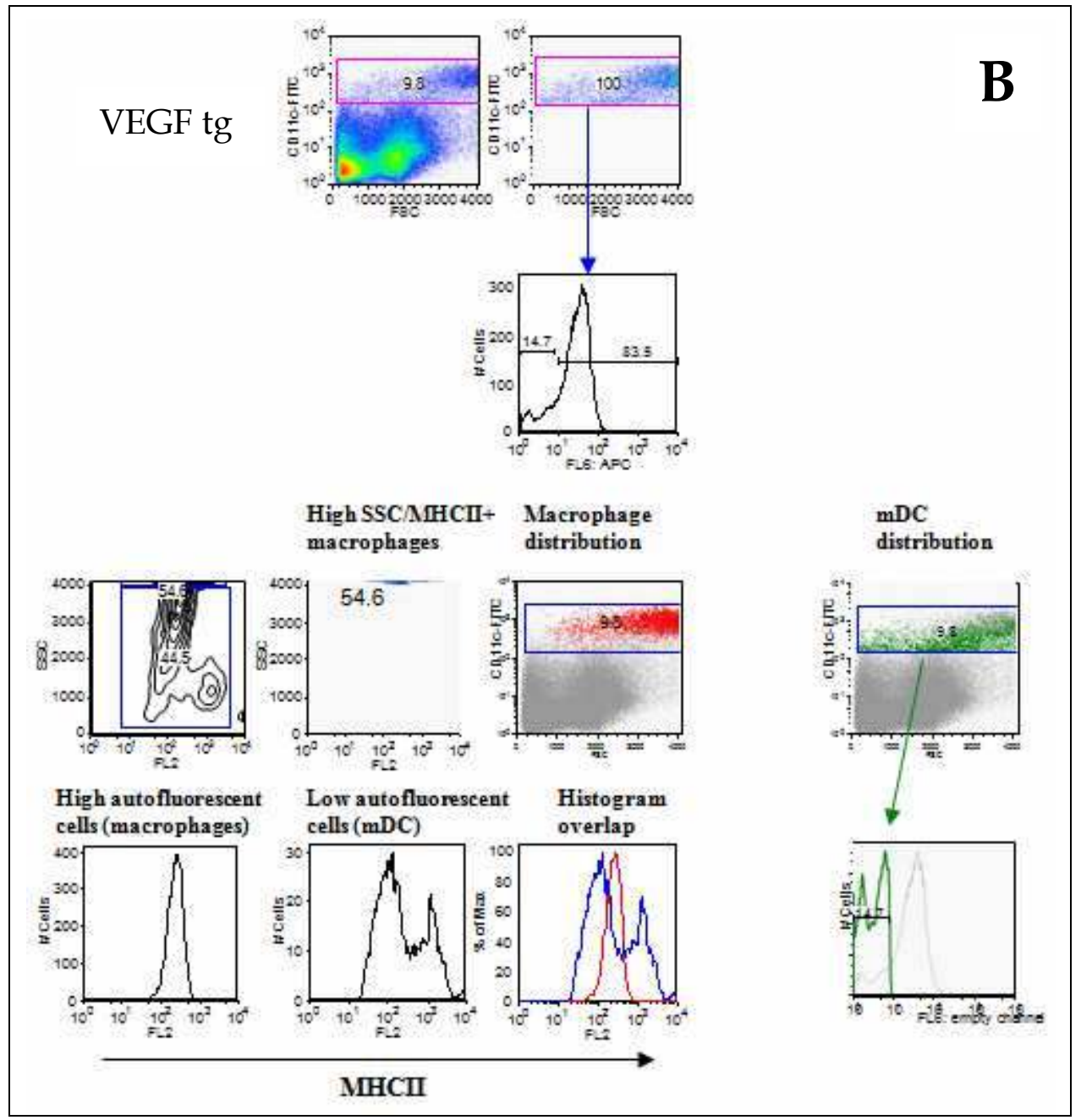

Fig. 5. Continued

We then further analyzed lung cDC using the defined above Abs to CD11c, MHCII, CD11b, DEC-205, and F4/80 cell surface markers in multicolour flow cytometry analysis using LSRII flow cytometer equipped with FACS Diva software. We identified lung CDC in WT mice as CD11c+MHCII+CD11b+F4/80 lowDEC-205low cells (Figure 6). Although it should be noted here that using anti-DEC-205 $\mathrm{Ab}$ for IHC of lung tissues we were able to detect an equal low number of DEC-205+ (a lectin-type receptor, (Pollard \& Lipscomb, 1990) cells between WT and VEGF tg mice without DOX-containing water exposure, and, therefore, in the absence of transgene expression (Chapoval et al., 2009; Lee et al., 2004). Lung VEGF tg cDC demonstrated the increased DEC-205 and MHCII and decreased F4/80 expression. Recently, mouse lung cDC were subdivided into two subpopulations, namely CD11b $+\mathrm{cDC}$ and CD103+ cDC (Beaty et al., 2007; Jakubzick, Tacke, et al., 2008; Sung et al., 2006). CD103 
A

\section{Conventional DC}
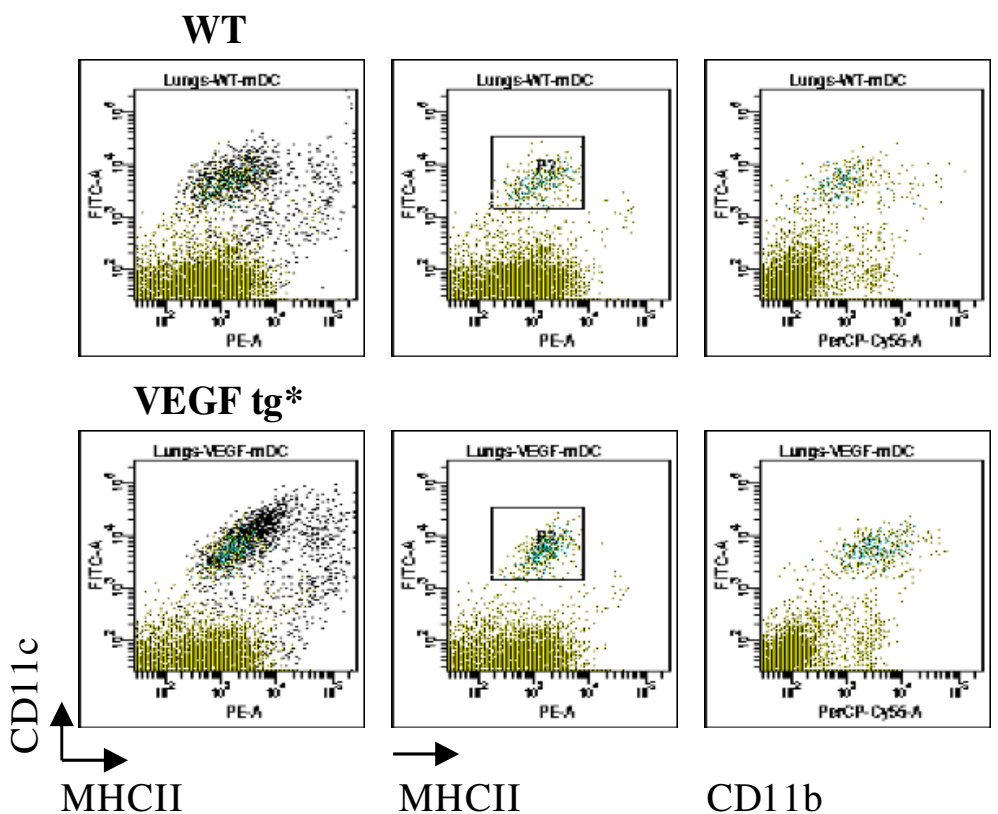

$B$
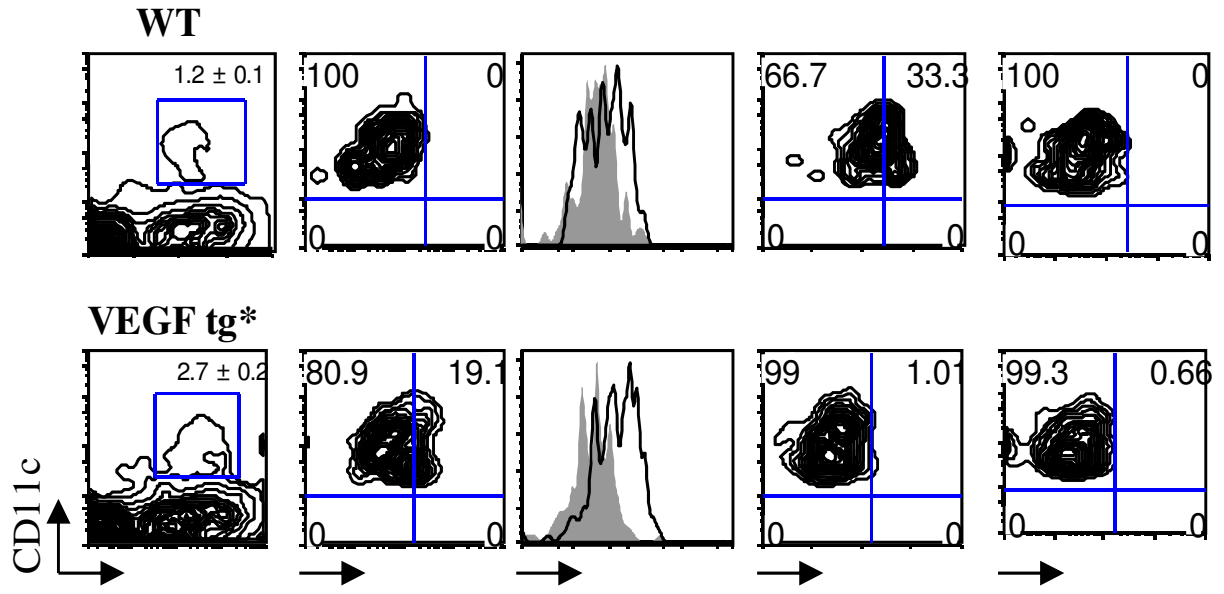

MHCII

DEC-205

DEC-205

$\mathrm{F} 4 / 80$

$\mathrm{cAb}$

Fig. 6. Conventional DC in the lungs of WT and VEGF tg mice 
is alpha E integrin which was detected on a subset of lung CDC and is also expressed on intraepithelial lymphocytes (Lehmann et al., 2002). Nevertheless, the use of this marker the helped to subdivide mouse lung tissue DC on three subclasses, pDC, CD11b+ cDC and CD103+ cDC (Beaty et al., 2007; Jakubzick, Helft, Kaplan, \& Randolph, 2008; Lambrecht et al., 2000; Sung et al., 2006).

Lung cells were stained with CD11c-FITC, MHCII-PE, and CD11b-PerCP. The cells were first analyzed for forward and side scatters and gated out as shown in the blue box. Lung cDC in WT and VEGF tg mice were defined using CD11c-FITC marker and FL6 empty channel (Jakubzick, Helft, et al., 2008; Jakubzick, Tacke, et al., 2008; K. Vermaelen \& Pauwels, 2004). CD11c/F16 dot plots of this gated population showed two CD11chigh WT cDC subpopulations $(180+585$ cells for WT mouse lungs). Both of them were not autofluorescent in WT mice. These cells were then back-gated on the FCS and SSC dot plot. Dot plot distribution of selected cells is shown in red color. The relative and absolute numbers of the mainly macrophage-gate containing portion of WT lung cDC are equaled $2.25 \%$ / 585 cells. In contrast, the relative and absolute numbers of the portion of VEGF tg CDC were significantly higher than those found in WT mice and equaled 2.97\% / 1961 cells. Population of $\operatorname{tg}$ lung CDC (2.25\% of gated cells) showed low autofluorescence in empty FL6.

Single cell suspensions obtained from mouse lungs with omitting the enzymatic digestion step (Piggott et al., 2005) were stained with CD11c-FITC, MHCII-PE, and CD11b-PerCP. CD11chigh cells were gated out and analyzed for MHCII expression vs SSC. Two subpopulations of MHCII+ cells were observed in WT mouse lungs, namely SSClowMHCII+ $(84.1 \%)$ cells and SSChighMHCII+ $(14.4 \%)$ cells. The SSChighMHCII+ cells composed of autofluorescent lung macrophages and they are shown in red. Most of these cells are located on the border line of SSC and where gated out in further lung CDC analysis. Lung CDC are shown in green. Lower panel for WT mice shows that both populations of autofluorescent macrophages and cDC overlap on MHCII histogram. This also applies for VEGF tg lung macrophages and cDC (two lower panels). In VEGF tg mouse lungs the number of CD11c+ SSChighMHCII+ macrophages mounted to $54.6 \%$ of CD11c+ cells. Similarly to WT mice, these cells were located on the border line of SSC and where gated out from further cDC analysis.

These cells were not macrophages since macrophages were more autofluorescent and shifted more to up and right on FL6 empty channel. When macrophages were added to the dot plot, a significantly higher number of cells (8.68\% / 12875 cells) in this selection box was observed. Therefore, there is a significant overlap between CDC and CD11chigh lung macrophages with a gating strategy based on CD11c marker and an empty channel autofluorescence.

In human, lung $\mathrm{CDC}$ were characterized in the enzymatically digested tissues obtained at the lung surgery (Masten et al., 2006). cDC were defined as CD1c+CD11c+CD14- HLA-DR+ cells which comprised $2 \%$ of low autofluorescent mononuclear cells in a flow cytometry analysis. The expression of CD14 together with CD11c are critical important distinguishing markers for lung $\mathrm{CDC}$ and macrophages, as monocytes and macrophages were CD11cCD14+ whereas CD11c+ cDC did not express CD14. Similarly to the mouse lung DC, human lung DC in a steady state condition are in immature state as defined by the absence of expression of differentiation markers CD83 and CD1a and limited expression of 
costimulatory molecules (Cochand et al., 1999). In the latter study, the loosely adherent on the Petri dishes cells were further separated into DC and autofluorescent macrophages with a Coulter EPICS V based on the presence or absence of autofluorescent inclusions with a coherent INNOVA 90 light source, using a 488-nm wavelength for excitation and a 588-nm filter for emission. The gates were set to remove cell debris and to select mature alveolar macrophages and nonphagocytic DC.

\subsubsection{Lung plasmacytoid DC}

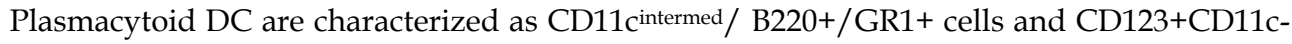
CD14-HLA-DR+ cells in mice and human, correspondingly (Chapoval et al., 2009; de Heer et al., 2004; Masten et al., 2006; Ritz et al., 2004). Plasmacytoid DC in the mouse lungs were first properly detected and functionally analyzed by Bart Lambrecht's group in 2004 (de Heer et al., 2004). This discrimination was based on CD11c and GR1 expression. The sorted cells based on this discrimination characteristic showed typical morphologies for different cell types such as eosinophils, lymphocytes, macrophages, neutrophils, and DC. pDC were targeted to the specific region based on CD11c and GR-1 expression, displayed a more immature phenotype than $\mathrm{CDC}$ and were $\mathrm{MHCII}{ }^{\text {low, }} \mathrm{B} 220+$ and $\mathrm{CD} 45 \mathrm{RB}+$. Confocal microscopy targeted $\mathrm{B} 220+\mathrm{Gr} 1+\mathrm{pDC}$ to the lung interstitium. The elimination of these cells with the in vivo use of anti-GR1 or 120G8 depleting Abs lead to the allergic eosinophilic response in the lungs to normally inert allergen applications (Asselin-Paturel, Brizard, Pin, Briere, \& Trinchieri, 2003; de Heer et al., 2004).

Lung VEGF expression increases the number of $\mathrm{cDC}$ in tg mouse lungs. Mouse lung tissues were obtained on day 7 of DOX water administration and processed using the enzymatic digest method. Single cell suspensions were stained with corresponding $\mathrm{Ab}$ and analyzed by flow cytometry. (A-B) Autofluorescent macrophages (shown in black color in panel A) were removed from the DC analysis. An upregulation of MHCII, CD11b, DEC-205 but not F4/80 expression on tg lung cDC was detected. For histograms: solid line represents isotype control rat IgG2a staining whereas transparent line shows the level of DEC-205 expression. ${ }^{*} \mathrm{p}<0.0025$, WT vs tg lung mDC number ( $\mathrm{n}=5$ /group).

We studied the effect of lung VEGF expression on local pDC number and activation employing VEGF tg mice (Chapoval et al., 2009). We have found that VEGF induced activation of lung pDC which were characterized as CD11cintB220+GR1+ cells and upregulated MHCII, CD40, CD80, and CD86 without a substantial modulation of ICOS-L expression.

Human lung plasmacytoid DC were characterized as CD123+CD11c+CD14+HLA-DR+ cells and comprised approximately $1.0 \%$ of the low autofluorescent mononuclear cells in flow cytometry analysis of cells from the lung tissues obtained upon surgery (Masten et al., 2006). A first discrimination of DC in this study was based on CD11c and CD14 expression. Morphological examination of cytospinned cells revealed cDC enriched CD11c+CD14- cell population and pDC-enriched CD11c-CD14- cell population. These populations were further analyzed for CD3, CD19, and CD56 expression to distinguish T, B and NK cells. The elimination of these cells subsets from the analysis demonstrated that approximately $7 \%$ of CD11c-CD14-human lung cell population were pDC. A lectin type receptor BDCA-2 (Demedts, Brusselle, Vermaelen, \& Pauwels, 2005) expression was present only on 9 out of 
13 samples analyzed. Unexpectedly, BDCA-2 expression was also seen in the cDC subpopulation, raising concerns about the pDC specificity of this marker for lung DC. Of note, BDCA-2 is not present in mice, and Siglec-H is used to define mouse pDC (Steinman, 2010).

\subsubsection{Other lung DC subtypes arising under different conditions}

Maraskovsky E and associates (Maraskovsky et al., 1996) were first to demonstrate that in vivo injections of Flt3L (FMS-related tyrosine kinase 3 ligand) into the mice will lead to a dramatic increase of DC subpopulations in different organs including the lungs. Five DC subpopulations were detected in spleens of injected mice based mainly on CD8 $\alpha$ and CD11b expression, namely

1. CD11b brightMHCII-GR1+CD11c-,

2. CD11b bright $\mathrm{CD} 11 \mathrm{c}^{\text {dull } M H C I I+G R 1+,}$

3. CD11b bright CD11c+MHCII+GR1-,

4. CD11bdull CD11c+MHCIIbrightGR1-, and

5. CD11b-CD11c+MHCII brightGR1- cells.

Populations (1-3) were also CD8 $\alpha+$, whereas DC in (4-5) were not expressing this lymphoid cell marker. Population (1) was highly enriched with immature granulocytes or myeloid cells as determined with Wright-Giemsa stain of sorted cell's cytospin. Last two DC subpopulations were highly enriched for veiled cells with dendritic processes. When compared for $\mathrm{T}$ cell stimulation activity, all 1-5 population were able to stimulate allogeneic T cells in MLR, however, DC in populations 1-2 were 30-times less efficient as compared to control freshly isolated DC. For distinguishing lung DC populations affected by Flt3L injections, the authors used DEC-205 as a selection marker considering a previously reported CD11c expression on a subset of lung macrophages. They noted a strong 8-15-times fold elevation in relative numbers of DEC-205+CD11b+ and DEC-205+CD11b- cells. A more recent publication by Masten BJ and associates (Masten, Olson, Kusewitt, \& Lipscomb, 2004) focused on Flt3L injection's effect specifically on lung DC. Flt3L induced a 19-fold increase in the absolute numbers of CD11c+CD45R/B220-DC in the lungs of Flt3L-treated mice over vehicle-treated mice. Further analysis revealed a 90-fold increase in the absolute number of myeloid DC (CD11c+CD45R/B220-CD11b+ cells) and only a 3-fold increase of lymphoid DC (CD11c+CD45R/B220-CD11b- cell) from the lungs of Flt3L-treated mice over vehicletreated mice. The authors noted 4 subpopulations of lung DC under the study conditions, namely: (1) myeloid CD11b+ CD45R/B220- DC, (2) lymphoid CD11b- CD45R/B220- DC, (3) and (4) plasmacytoid DC expressing various levels of CD11c and CD45R/B220 markers. Therefore, the use of Flt3L may be efficient in augmenting vaccine responses against different lung infectious agents and promoting anti-tumor responses. However, as for the dampening of allergic lung responses, it might not be as effective considering the fact that myeloid lung DC which are mainly upregulated by Fl3L treatment, are necessary for allergic lung response generation and sustainability (Lambrecht et al., 2000; Lambrecht, Salomon, Klatzmann, \& Pauwels, 1998).

A very detailed classification of DC based on organ and tissue distribution, marker's (including chemokine receptors) expression, migration, and function was recently presented in a comprehensive review article by Alvarez, Vollmann, and von Andrian (Alvarez, 
Vollmann, \& von Andrian, 2008) (Table 1 shows a fraction of a table presented in this comprehensive review). As for lung DC, the authors focused only on two myeloid DC subpopulations distinguished mainly by CD103 expression, lung interstitium CD11bloCD11c+CD103+ and conducting airway CD11bhiCD11c+Cd103- DC.

\begin{tabular}{|c|c|}
\hline Dendritic cell subset & Phenotype \\
\hline \multicolumn{2}{|l|}{ Precursor DC } \\
\hline $\begin{array}{l}\text { Hematopoietic stem and } \\
\text { progenitor cell (HSPC) }\end{array}$ & CD45+Lin-c-Kit+Sca-1+ \\
\hline $\begin{array}{l}\text { Macrophage DC precursor } \\
\text { (MDP) }\end{array}$ & CD44+Lin-c-KitintCD11b- \\
\hline $\begin{array}{l}\text { Common dendritic } \\
\text { projenitor (CDP) }\end{array}$ & CD44+Lin-c-KitintFlt3+ \\
\hline Monocyte subsets & CD115+CD11b+Ly6C low/int/hi F4/80lowCD62L+/- \\
\hline \multicolumn{2}{|l|}{ Differentiated DC } \\
\hline Langerhans cell & $\begin{array}{l}\text { Langerin+MHCII+Dectin- } \\
\text { 1+CD1a+CD11c+CD11b+CD24a+CD205+CD45loCD8a+/- } \\
\text { CD103- }\end{array}$ \\
\hline $\begin{array}{l}\text { Dermal DC (langerin+ } \\
\text { subset) }\end{array}$ & Langerin+MHCII+CD11 $c^{\text {int }}$ CD11blo CD45hiCD8a+CD103+ \\
\hline $\begin{array}{l}\text { Dermal DC (langerin- } \\
\text { subset) }\end{array}$ & Langerin-MHCII+CD11c+ CD24a-DEC205+ \\
\hline CD8a+DC & CD8a+MHCII+CD11c+CD4-CD205+SIRP-a+ \\
\hline CD8a-DC & CD8a-MHCII+CD11c+CD11b+CD4-SIRP-a+DCIR2+ \\
\hline CD8a-CD4+DC & CD8a-CD4+CD11b+MHCII+DCIR2+ \\
\hline Plasmacytoid DC & $\begin{array}{l}\text { B220+CD11c }{ }^{\mathrm{lo}} \mathrm{Ly} 6 \mathrm{C}+\mathrm{MHCII}{ }^{\mathrm{lo} C D} 4+/-\mathrm{CD} 8 \mathrm{a}+/-\mathrm{PDCA}-1+ \\
\text { (human: CD123+BDCA-2+BDCA-4+) }\end{array}$ \\
\hline $\begin{array}{l}\text { Lung DC ( } 2 \text { subsets) } \\
\text { Conducting airway DC } \\
\text { Lung interstitium DC }\end{array}$ & $\begin{array}{l}\text { CD11bloCD11c+CD103- } \\
\text { CD11bloCD11c+CD103+ }\end{array}$ \\
\hline $\begin{array}{l}\text { Lamina propria DC (4 } \\
\text { subsets) }\end{array}$ & $\begin{array}{l}\text { CD11chiCD11b-CD205+CD103+ } \\
\text { CD11chiCD11b+CD205+CD103+ } \\
\text { CD11cintCD11bintCD205-CD103- } \\
\text { CD11cintCD11b+CD205-CD103- }\end{array}$ \\
\hline $\begin{array}{l}\text { Peyer's patch DC ( } 3 \\
\text { subsets) }\end{array}$ & $\begin{array}{l}\text { CD11c+CD8a+CD11b- } \\
\text { CD11c+CD8a+CD11b+ } \\
\text { CD11c+CD8a-CD11b- }\end{array}$ \\
\hline
\end{tabular}

Table 1. Phenotype of dendritic cell subsets (modified from (Alvarez, Vollmann et al. 2008)

Finally, a unifying classification of human and mouse DC subsets was recently proposed by Guilliams $\mathrm{M}$ and associates (Guilliams et al.) which takes into account a functional specialization and specific marker expression (Figure 7). This classification is based on the expression of CD11b, CD103, and CD207. It highlights many unanswered questions in the DC research including the proper cell determination. 


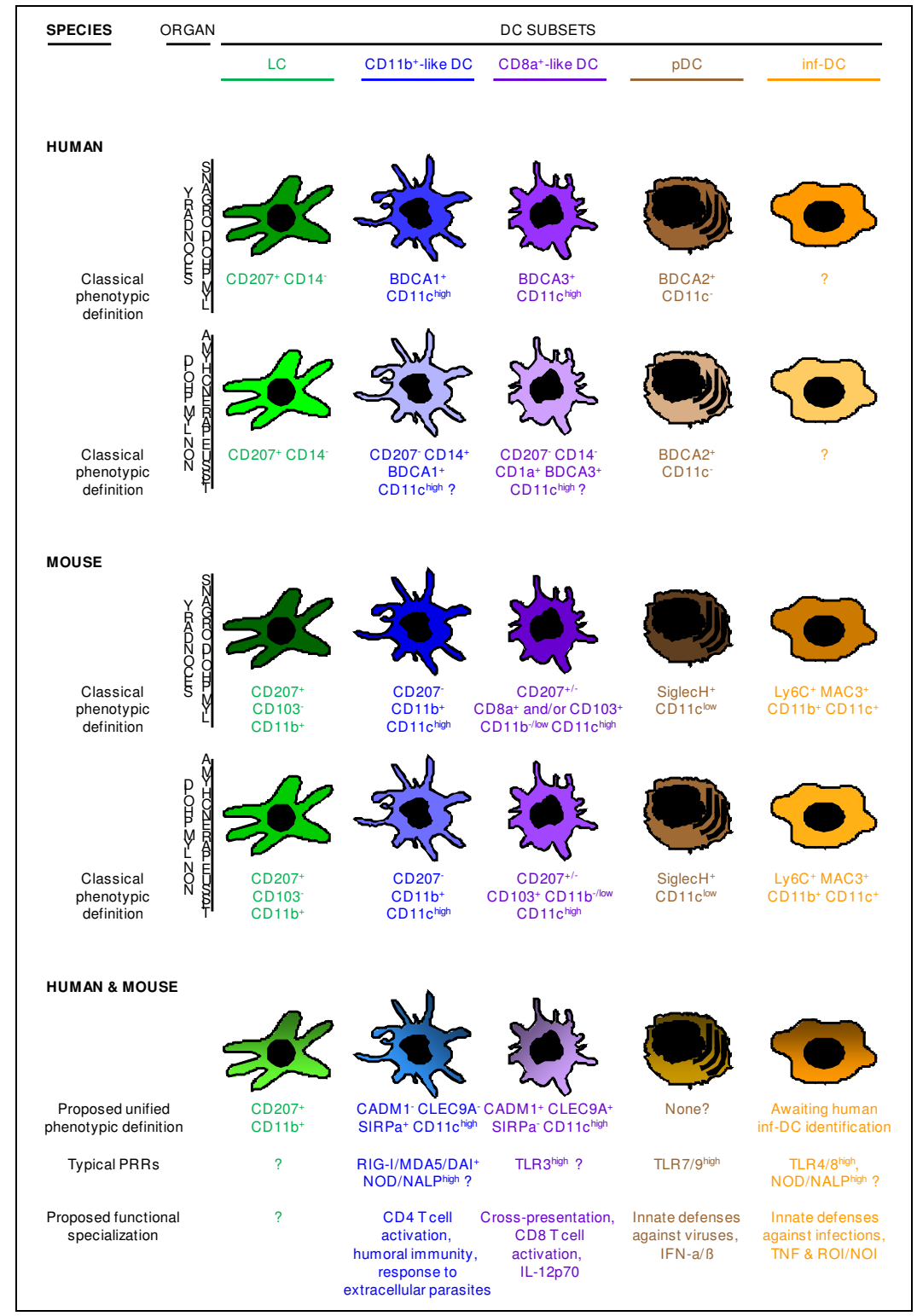

Fig. 7. A unifying model of human and mouse DC subsets (courtesy of Bernard Malissen). Human and mouse DC subsets were organized into five broad subsets irrespective of their primary location/tissue origin. These five subsets correspond to: (1) Langerhans cells (green), (2) DC-like cells (blue), (3) CD8a+ DC-like cells (violet), (4) pDC (brown), and (5) monocyte-derived inf-DC (orange). The authors suggest a general nomenclature for each DC subset (lower row, shaded colors) which is based on the unified phenotypic definition, characteristic pattern recognition receptors and functional specialization 


\section{Functional characteristics of lung DC}

As mentioned above, the crucial functions of DC are to capture antigens throughout the body, migrate to the local lymphoid organs to deliver Ag and stimulate or tolerize $\mathrm{T}$ cells. The in vitro and in vivo Ag sampling by DC can be easily and specifically measured by flow cytometry (Chapoval et al., 2009; Cleret et al., 2007; Lambrecht et al., 2000; K. Y. Vermaelen et al., 2001; K. Y. Vermaelen et al., 2003). When DC acquire Ag, they become mature, upregulate their adhesion and costimulatory molecule expression, and specifically regulate chemokine receptor expression what makes them attracted to the lymphoid tissue (McColl, 2002). Ag-stimulated peripheral organ/tissue DC which downregulated inflammatory chemokine expression and upregulated CCR7 migrate to the local lymphoid tissue. These cells are called activated DC (McColl, 2002).

\subsection{DC activation and maturation}

As mentioned above, DC populate the lung tissue in the immature state (K. Vermaelen \& Pauwels, 2005). Immature DC display high endocytic abilities and low T cell stimulation activity (Figure 1). After antigen uptake, DC undergo a complex process called maturation when they upregulate adhesion and costimulatory molecule expression and cytokine production but shut down the antigen-capturing activity. The DC conversion from immature to mature state is accompanied by a marked cellular reorganization (Shin et al., 2006) which can be detected by flow cytometry. This includes the redistribution of MHC II molecules from late endosomal and lysosomal compartments to the plasma membrane (Trombetta \& Mellman, 2005; Turley et al., 2000). In addition, as mentioned above, DC downregulate their Ag uptake ability. This downregulation of some forms of endocytosis slows the clearance of MHC II from the cell surface (Sallusto, Cella, Danieli, \& Lanzavecchia, 1995; Wilson, El-Sukkari, \& Villadangos, 2004). Shin J-S and associates have determined the regulation of surface MHC II (Shin et al., 2006) employing bone marrow-derived DC expressing WT MHCII or mutant MHCII $\beta$ (where single lysine of $\beta$-chain cytoplasmic domain was replaced with arginine, $\mathrm{K}>\mathrm{R}$ ) in flow cytometry. They have demonstrated that the MHC II $\beta$-chain cytoplasmic tail is ubiquitinated in mouse immature DC. Although only partly required for the sequestration MHC II in multivesicular bodies, this modification is essential for endocytosis. Notably, ubiquitination of MHC II was significantly downregulated with DC maturation, resulting in the cell surface accumulation of MHC II. Therefore, DC demonstrate a unique ability to regulate MHC II surface expression by selectively controlling MHC II ubiquitination.

\subsection{Costimulatory molecule expression and function}

In steady state conditions, lung cDC are immature and express CD11c, CD11b, low MHCII and low DEC-205 (Chapoval et al., 2009). The levels of costimulatory molecule expression on these cells vary from low to absent. To determine the effect of lung VEGF expression on local DC maturation state, we performed a flow cytometry analysis of lung digest single cell suspensions using the following marker-specific Abs for detection of costimulatory molecule expression on lung DC: anti-CD40-PE (3.23), anti-CD54-PE (3E2), anti-CD80-PE (16-10A1), anti-CD86-PE (GL1) PE-labeled, all from BD Biosciences. Anti-B7h/ICOS-L (HK5.3) Ab was obtained from eBioscience (Bhandari et al., 2006; Lee et al., 2004). PEconjugated rat IgG2a (R35-95) and rat IgG2b (R35-38) were used as isotype controls. VEGF 
expression induced lung cDC activation as they upregulate MHCII, CD40, CD80, CD86, and CD54 expression on their surface (Lee et al., 2004).

\subsection{In vivo antigen uptake}

To track the Ag uptake by lung DC in vivo, we applied $1 \mu \mathrm{g} / 50 \mu \mathrm{l} /$ mouse of OVA-FITC i.n. to WT and VEGF tg mice one time (Chapoval et al., 2009). Lung tissue and local LN digests were analyzed by flow cytometry $6 \mathrm{~h}$ and $24 \mathrm{~h}$ after Ag application for FITC+ cells using CD11c/MHCII/CD11b markers. We observed an increase in FITC+ DC but not Mac-1+ cell number in VEGF tg lungs by flow cytometry. Therefore, intermediately mature cDC obtained from the lung of VEGF tg mice were more efficient in Ag uptake.

Intratracheal instillations of OVA-FITC to mice with different deficiency can be used to assess the effect of such deficiency on lung DC migration. As an example, Vermaelen and associates (K. Y. Vermaelen et al., 2003) used OVA-FITC in MMP-9-/- mice to evaluate the effect of MMP-9 deficiency on lung DC migration. The study has shown that FITC+ cells gradually accumulate in the draining lymph nodes with a peak reaching at $24 \mathrm{~h}$ of $\mathrm{Ag}$ application with no difference in lung DC migration between WT and MMP-9-/- mice.

\section{Lung DC sorting}

Highly pure isolated populations of DC are needed to evaluate their exact biological properties and function. Despite the fact that most lung DC represent rare populations among other lung cells, the high level of DC purification could be reached with either immunomagnetic (f.e. MACS technology, Milenyi Biotech) cell separation or flow cytometry-based cell sorts.

\subsection{Methods of sorting}

Lung conventional DC were sorted using a triple marker combination (CD11c/MHCII/ CD11b) employing BD FACS Vantage or BD FACS Aria (both equipped with FACSDiva software), or Dako MoFlo (Summit software) high speed automated cell sorters (Chapoval et al., 2009) which all provide the state-of-the-art advances in the instrument set-up, cell sorting and integrated cell analysis. Autofluorescent macrophages and cell doublets are eliminated from further analysis by proper gating (Chapoval et al., 2009). The cDC sorting strategy is shown in Figure 8.

\subsection{Analyses of sorted lung DC}

Sorted lung DC then could be used in different in vitro assays to define the specific protein expression which could be further analyzed by flow cytometry (Beaty et al., 2007; Chapoval et al., 2009; K. Y. Vermaelen et al., 2001). The in vitro Ag uptake is an important technique to define the maturation status of DC and its functional activity. To study the in vitro Ag uptake, we subjected lung cells and sorted lung $\mathrm{cDC}$ to the in vitro cultures with or without increasing doses of OVA-FITC (Molecular Probes) ranging from $0.01 \mathrm{mg} / \mathrm{ml}$ to $1 \mathrm{mg} / \mathrm{ml}$ in RPMI (Life Technologies) in 24-well plates (Costar) for $30 \mathrm{~min}$ at $37^{\circ} \mathrm{C}$. After incubation, cells were extensively washed with RPMI medium and analyzed for Ag uptake by flow cytometry. VEGF tg mDC are significantly more efficient in Ag uptake with low doses of Ag used. For example, at $10 \mu \mathrm{g}$ of Ag only $30.2 \%$ of WT DC were FITC+ whereas for VEGF tg 
DC this number increased to $73.9 \%$. At high dose both WT and $\operatorname{tg} \mathrm{CDC}$ are equally efficient in Ag uptake.

\subsection{Intracellular staining for cytokine and chemokine expression by DC}

Chemokine production by lung CD11c+ cells was studied using intracellular staining (Beaty et al., 2007). Lung DC were sorted using anti-CD11c-conjugated magnetic microbeads (Miltenyi Biotec). pDC were enriched from the flow-through CD11c- cells using antimPDCA-1 magnetic microbeads and further sorted as PDCA-1+B220+I-A int low scattered cells. CD11c+ cell fraction was further separated into subpopulations (CD103+ DC and CD11bhiDC) by cell sorting on Vantage SE sorter with FACSDiva sofrware (BD Biosciences). The authors demonstrated that lung DC even without stimulation have accumulated detectable amounts of many chemokines and cytokines. Readily detectable were MIP-2, IP10, MIP-1a, MIP-1b, RANTES, CXCL16, C10, TARC, and MDC for CD11bhi DC. Lung CD103+ DC expressed MIP-1a, CXCL16, TARC, and MDC but at much less levels. Therefore, the lung CD11bhi DC and CD103+ DC differentially express chemokines in naive mice. This difference further deepens with corresponding cell activation.

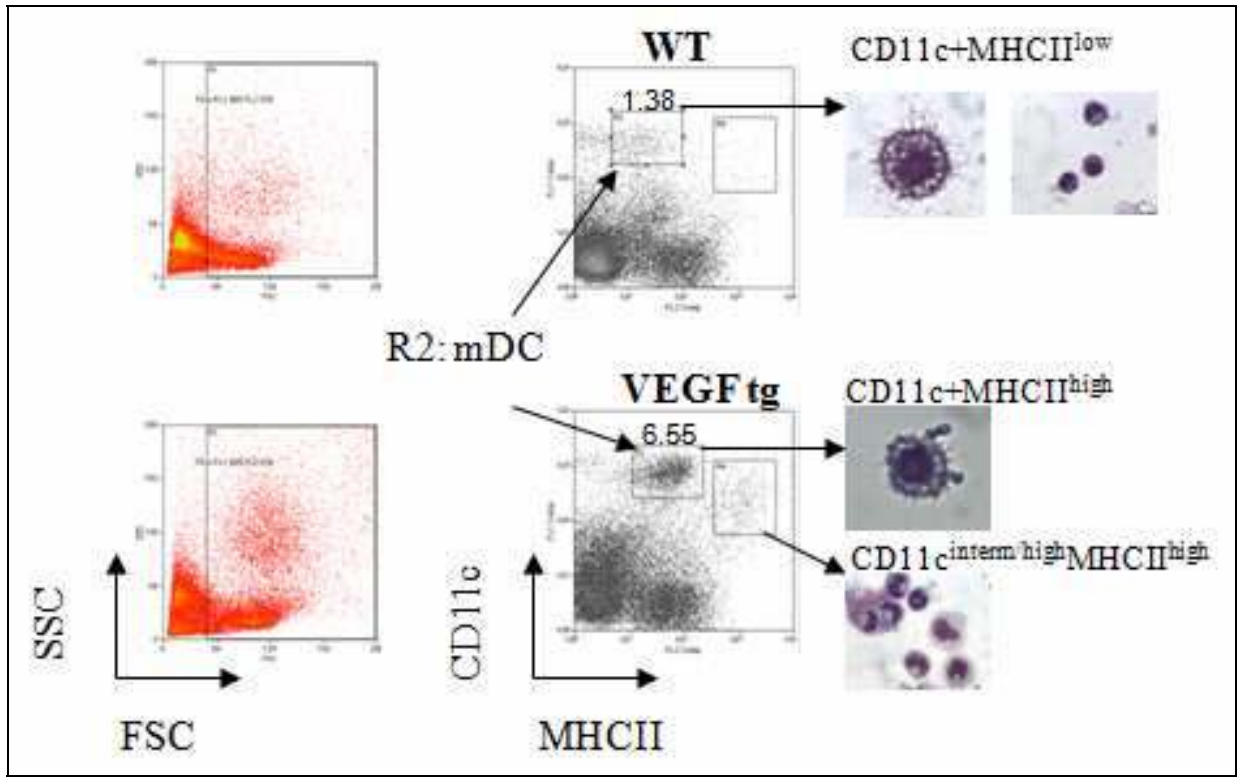

Fig. 8. Conventional lung DC acquisition and morphology. Single lung cell suspensions obtained from WT and VEGF tg mice ( $n=4-5$ mice per experiment) were prepared with an omitting the enzymatic digestions step (Chapoval et al., 2009; Piggott et al., 2005). Cell were stained with anti-CD11c, -CD11b, and -MHCII Abs and analyzed using either FACSDiva or Summit software on cell sorters. Assigned cell populations were sorted and analyzed morphologically by Diff-Quick stain of cytospin slides prepared with $100 \mathrm{ml}$ of sorted cells. The sorted cDC selected for further analysis represent CD11c+MHCIIlow population in WT mice and CD11c+MHCIIhigh population of cells in VEGF tg mice. The cells in gate 4

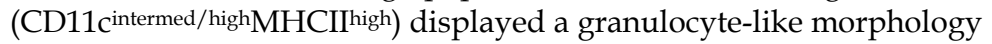




\subsection{In vivo DC migration study using sorted labeled cells}

In addition to the fluorescently-labeled Ag application directly to the airways to study the lung DC migration, lung sorted or bone marrow-derived labelled DC can be introduced to the airways to track their migration with a use of flow cytometry (Lambrecht et al., 2000). This approach helps to distinguish the lymph node resident DC and DC migrated there from the lung. Bone marrow CD11c+MHCII+CD86+HSA+CD44+ICAM-1+DC were pulsed with CFSE (carboxyfluoroscein succinimidyl ester) and $1 \times 10^{6}$ cells were instilled intratracheally into naive mice. DC were traced in the lungs and mediastinal lymph nodes at 12h, 36h, and 120h after application. The authors have demonstrated that CFSE+ DC could be detected in BALF, digested lung tissues, and draining lymph nodes by $12 \mathrm{~h}$ after instillation. By 36h CFSE+DC disappear from the BALF and intensively accumulate in the draining lymph nodes. A majority of injected cells had disappeared by $120 \mathrm{~h}$. Another study using this approach has demonstrated that by $24 \mathrm{~h}$ approximately $2 \%$ of draining lymph node cells were CFSE+DC migrated from the lungs (Legge \& Braciale, 2003). These CFSE+ DC were more mature than local DC as they showed higher levels of costimulatory molecule expression (CD40, CD80, and CD86) and upregulated MHCII expression.

Intratracheal adoptive transfer of CFSE-labeled exogenous DC has been used to study the effect of MMP-9 deficiency on DC trafficking from the lung to the mediastinal lymph nodes (K. Y. Vermaelen et al., 2003). Measuring the absolute numbers of FITC+ cells in the lymph nodes, they demonstrated no differences between MMP-9+ and MMP-9- DC reaching lymph nodes

\section{Summary}

In conclusion, we show and discuss in this chapter a high phenotypic and functional complexity of lung DC. None of DC subpopulation can be identified and isolated by cell sorting for further analysis based on one or two marker expression. Specific Abs at least to three-four molecules needed to be used simultaneously for a clear lung DC subpopulation differentiation. Multicolor flow cytometry measuring simultaneously 5 or more parameters has dramatically increased our ability in DC subtype biology characterization. However, the complexity of such analysis increases with the number of fluorochromes used. The use of appropriate gating strategy, inclusion of all necessary controls from the beginning of the experiment and all necessary isotype controls for the specific Abs used in the assay, proper instrument validation, correct compensation will highly contribute to obtaining relevant biological data.

\section{Acknowledgment}

S.P.C. is supported by NIAID R21AI076736 grant.

\section{References}

Alvarez, D., Vollmann, E. H., \& von Andrian, U. H. (2008). Mechanisms and consequences of dendritic cell migration. Immunity, 29(3), 325-342. 
Asselin-Paturel, C., Brizard, G., Pin, J. J., Briere, F., \& Trinchieri, G. (2003). Mouse strain differences in plasmacytoid dendritic cell frequency and function revealed by a novel monoclonal antibody. [Comparative Study]. J Immunol, 171(12), 64666477.

Beaty, S. R., Rose, C. E., Jr., \& Sung, S. S. (2007). Diverse and potent chemokine production by lung CD11bhigh dendritic cells in homeostasis and in allergic lung inflammation. J Immunol, 178(3), 1882-1895.

Bhandari, V., Choo-Wing, R., Chapoval, S. P., Lee, C. G., Tang, C., Kim, Y. K., . . Elias, J. A. (2006). Essential role of nitric oxide in VEGF-induced, asthma-like angiogenic, inflammatory, mucus, and physiologic responses in the lung.. Proc Natl Acad Sci $U$ $S$ A, 103(29), 11021-11026.

Chapoval, S. P., Nabozny, G. H., Marietta, E. V., Raymond, E. L., Krco, C. J., Andrews, A. G., David, C. S. (1999). Short ragweed allergen induces eosinophilic lung disease in HLA-DQ transgenic mice. J Clin Invest, 103(12), 1707-1717.

Chapoval, S. P., Al-Garawi, A., Lora, J. M., Strickland, I., Ma, B., Lee, P. J., Homer, R. J., Ghosh, S., Coyle, A. J., Elias, J. A. (2007). Inhibition of NF-kappaB activation reduces the tissue effects of transgenic IL-13. J Immunol, 179(10), 7030-7041.

Chapoval, S. P., Lee, C. G., Tang, C., Keegan, A. D., Cohn, L., Bottomly, K., \& Elias, J. A. (2009). Lung vascular endothelial growth factor expression induces local myeloid dendritic cell activation. Clin Immunol, 132(3), 371-384.

Chelen, C. J., Fang, Y., Freeman, G. J., Secrist, H., Marshall, J. D., Hwang, P. T., . . Umetsu, D. T. (1995). Human alveolar macrophages present antigen ineffectively due to defective expression of B7 costimulatory cell surface molecules. J Clin Invest, 95(3), 1415-1421.

Cleret, A., Quesnel-Hellmann, A., Vallon-Eberhard, A., Verrier, B., Jung, S., Vidal, D., . . . Tournier, J. N. (2007). Lung dendritic cells rapidly mediate anthrax spore entry through the pulmonary route. J Immunol, 178(12), 7994-8001.

Cochand, L., Isler, P., Songeon, F., \& Nicod, L. P. (1999). Human lung dendritic cells have an immature phenotype with efficient mannose receptors. Am J Respir Cell Mol Biol, 21(5), 547-554.

de Heer, H. J., Hammad, H., Soullie, T., Hijdra, D., Vos, N., Willart, M. A., . . Lambrecht, B. N. (2004). Essential role of lung plasmacytoid dendritic cells in preventing asthmatic reactions to harmless inhaled antigen. J Exp Med, 200(1), 89-98.

Demedts, I. K., Brusselle, G. G., Vermaelen, K. Y., \& Pauwels, R. A. (2005). Identification and characterization of human pulmonary dendritic cells. Am J Respir Cell Mol Biol, 32(3), 177-184.

Fainaru, O., Shseyov, D., Hantisteanu, S., Groner, Y. (2005). Accelerated chemokine receptor 7-mediated dendritic cell migration in Runx3 knockout mice and the spontaneous development of asthma-like disease. Proc Natl Acad Sci U S A, 102(30), 10598-10603.

Guilliams, M., Henri, S., Tamoutounour, S., Ardouin, L., Schwartz-Cornil, I., Dalod, M., \& Malissen, B. From skin dendritic cells to a simplified classification of human and mouse dendritic cell subsets. Eur J Immunol, 40(8), 2089-2094. 
Jakubzick, C., Helft, J., Kaplan, T. J., \& Randolph, G. J. (2008). Optimization of methods to study pulmonary dendritic cell migration reveals distinct capacities of DC subsets to acquire soluble versus particulate antigen. J Immunol Methods, 337(2), 121-131.

Jakubzick, C., Tacke, F., Ginhoux, F., Wagers, A. J., van Rooijen, N., Mack, M., . . Randolph, G. J. (2008). Blood monocyte subsets differentially give rise to CD103+ and CD103pulmonary dendritic cell populations. J Immunol, 180(5), 3019-3027.

Kawanami, O., Basset, F., Ferrans, V. J., Soler, P., \& Crystal, R. G. (1981). Pulmonary Langerhans' cells in patients with fibrotic lung disorders. Lab Invest, 44(3), 227-233.

Kirby, A. C., Raynes, J. G., \& Kaye, P. M. (2006). CD11b regulates recruitment of alveolar macrophages but not pulmonary dendritic cells after pneumococcal challenge. J Infect Dis, 193(2), 205-213.

Lambrecht, B. N., De Veerman, M., Coyle, A. J., Gutierrez-Ramos, J. C., Thielemans, K., \& Pauwels, R. A. (2000). Myeloid dendritic cells induce Th2 responses to inhaled antigen, leading to eosinophilic airway inflammation. J Clin Invest, 106(4), 551559.

Lambrecht, B. N., \& Hammad, H. (2009a). Biology of lung dendritic cells at the origin of asthma. Immunity, 31(3), 412-424.

Lambrecht, B. N., \& Hammad, H. (2009b). Lung dendritic cells: targets for therapy in allergic disease. Handb Exp Pharmacol(188), 99-114.

Lambrecht, B. N., Salomon, B., Klatzmann, D., \& Pauwels, R. A. (1998). Dendritic cells are required for the development of chronic eosinophilic airway inflammation in response to inhaled antigen in sensitized mice. J Immunol, 160(8), 4090-4097.

Lee, C. G., Link, H., Baluk, P., Homer, R. J., Chapoval, S., Bhandari, V., . . . Elias, J. A. (2004). Vascular endothelial growth factor (VEGF) induces remodeling and enhances TH2-mediated sensitization and inflammation in the lung. Nat Med, 10(10), 1095-1103.

Legge, K. L., \& Braciale, T. J. (2003). Accelerated migration of respiratory dendritic cells to the regional lymph nodes is limited to the early phase of pulmonary infection. Immunity, 18(2), 265-277.

Lehmann, J., Huehn, J., de la Rosa, M., Maszyna, F., Kretschmer, U., Krenn, V., . . Hamann, A. (2002). Expression of the integrin alpha Ebeta 7 identifies unique subsets of CD25+ as well as CD25- regulatory T cells. Proc Natl Acad Sci U S A, 99(20), 1303113036.

Lindquist, R. L., Shakhar, G., Dudziak, D., Wardemann, H., Eisenreich, T., Dustin, M. L., \& Nussenzweig, M. C. (2004). Visualizing dendritic cell networks in vivo. Nat Immunol, 5(12), 1243-1250.

Maraskovsky, E., Brasel, K., Teepe, M., Roux, E. R., Lyman, S. D., Shortman, K., \& McKenna, H. J. (1996). Dramatic increase in the numbers of functionally mature dendritic cells in Flt3 ligand-treated mice: multiple dendritic cell subpopulations identified. J Exp Med, 184(5), 1953-1962. 
Masten, B. J., Olson, G. K., Kusewitt, D. F., \& Lipscomb, M. F. (2004). Flt3 ligand preferentially increases the number of functionally active myeloid dendritic cells in the lungs of mice. J Immunol, 172(7), 4077-4083.

Masten, B. J., Olson, G. K., Tarleton, C. A., Rund, C., Schuyler, M., Mehran, R., . . Lipscomb, M. F. (2006). Characterization of myeloid and plasmacytoid dendritic cells in human lung. J Immunol, 177(11), 7784-7793.

McColl, S. R. (2002). Chemokines and dendritic cells: a crucial alliance. Immunol Cell Biol, 80(5), 489-496.

Metlay, J. P., Witmer-Pack, M. D., Agger, R., Crowley, M. T., Lawless, D., \& Steinman, R. M. (1990). The distinct leukocyte integrins of mouse spleen dendritic cells as identified with new hamster monoclonal antibodies. J Exp Med, 171(5), 17531771.

Niu, N., Le Goff, M. K., Li, F., Rahman, M., Homer, R. J., \& Cohn, L. (2007). A novel pathway that regulates inflammatory disease in the respiratory tract. J Immunol, 178(6), 38463855 .

Piggott, D. A., Eisenbarth, S. C., Xu, L., Constant, S. L., Huleatt, J. W., Herrick, C. A., \& Bottomly, K. (2005). MyD88-dependent induction of allergic Th2 responses to intranasal antigen. J Clin Invest, 115(2), 459-467.

Pollard, A. M., \& Lipscomb, M. F. (1990). Characterization of murine lung dendritic cells: similarities to Langerhans cells and thymic dendritic cells. J Exp Med, 172(1), 159167.

Ray, P., Tang, W., Wang, P., Homer, R., Kuhn, C., Flavell, R. A., Elias, J. A. (1997). Regulated overexpression of interleukin 11 in the lung. Use to dissociate developmentdependent and -independent phenotypes. J Clin Invest, 100(10), 2501-2511.

Ritz, S. A., Cundall, M. J., Gajewska, B. U., Swirski, F. K., Wiley, R. E., Alvarez, D., . . . Jordana, M. (2004). The lung cytokine microenvironment influences molecular events in the lymph nodes during Th1 and Th2 respiratory mucosal sensitization to antigen in vivo. Clin Exp Immunol, 138(2), 213-220.

Sallusto, F., Cella, M., Danieli, C., \& Lanzavecchia, A. (1995). Dendritic cells use macropinocytosis and the mannose receptor to concentrate macromolecules in the major histocompatibility complex class II compartment: downregulation by cytokines and bacterial products. J Exp Med, 182(2), 389-400.

Sertl, K., Takemura, T., Tschachler, E., Ferrans, V. J., Kaliner, M. A., \& Shevach, E. M. (1986). Dendritic cells with antigen-presenting capability reside in airway epithelium, lung parenchyma, and visceral pleura. J Exp Med, 163(2), 436-451.

Shin, J. S., Ebersold, M., Pypaert, M., Delamarre, L., Hartley, A., \& Mellman, I. (2006). Surface expression of MHC class II in dendritic cells is controlled by regulated ubiquitination. Nature, 444(7115), 115-118.

Solovjov, D. A., Pluskota, E., \& Plow, E. F. (2005). Distinct roles for the alpha and beta subunits in the functions of integrin alphaMbeta2. J Biol Chem, 280(2), 13361345.

Spencer, S. C., \& Fabre, J. W. (1990). Characterization of the tissue macrophage and the interstitial dendritic cell as distinct leukocytes normally resident in the connective tissue of rat heart. J Exp Med, 171(6), 1841-1851. 
Steiniger, B., Klempnauer, J., \& Wonigeit, K. (1984). Phenotype and histological distribution of interstitial dendritic cells in the rat pancreas, liver, heart, and kidney. Transplantation, 38(2), 169-174.

Steinman, R. M. (2010). Some active areas of DC research and their medical potential. Eur J Immunol, 40(8), 2085-2088.

Steinman, R. M., \& Cohn, Z. A. (1973). Identification of a novel cell type in peripheral lymphoid organs of mice. I. Morphology, quantitation, tissue distribution. J Exp Med, 137(5), 1142-1162.

Sung, S. S., Fu, S. M., Rose, C. E., Jr., Gaskin, F., Ju, S. T., \& Beaty, S. R. (2006). A major lung CD103 (alphaE)-beta7 integrin-positive epithelial dendritic cell population expressing Langerin and tight junction proteins. J Immunol, 176(4), 2161-2172.

Swanson, K. A., Zheng, Y., Heidler, K. M., Zhang, Z. D., Webb, T. J., \& Wilkes, D. S. (2004). Flt3-ligand, IL-4, GM-CSF, and adherence-mediated isolation of murine lung dendritic cells: assessment of isolation technique on phenotype and function. J Immunol, 173(8), 4875-4881.

Trombetta, E. S., \& Mellman, I. (2005). Cell biology of antigen processing in vitro and in vivo. Annu Rev Immunol, 23, 975-1028.

Tsoumakidou, M., Tzanakis, N., Papadaki, H. A., Koutala, H., Siafakas, N. M. (2006). Isolation of myeloid and plasmacytoid dendritic cells from human bronchoalveolar lavage fluid. Immunol Cell Biol, 84(3), 267-273.

Turley, S. J., Inaba, K., Garrett, W. S., Ebersold, M., Unternaehrer, J., Steinman, R. M., \& Mellman, I. (2000). Transport of peptide-MHC class II complexes in developing dendritic cells. Science, 288(5465), 522-527.

van Haarst, J. M., Hoogsteden, H. C., de Wit, H. J., Verhoeven, G. T., Havenith, C. E., Drexhage, H. A. (1994). Dendritic cells and their precursors isolated from human bronchoalveolar lavage: immunocytologic and functional properties. Am J Respir Cell Mol Biol, 11(3), 344-350.

Vermaelen, K., \& Pauwels, R. (2004). Accurate and simple discrimination of mouse pulmonary dendritic cell and macrophage populations by flow cytometry: methodology and new insights. Cytometry A, 61(2), 170-177.

Vermaelen, K., \& Pauwels, R. (2005). Pulmonary dendritic cells. Am J Respir Crit Care Med, 172(5), 530-551.

Vermaelen, K. Y., Carro-Muino, I., Lambrecht, B. N., \& Pauwels, R. A. (2001). Specific migratory dendritic cells rapidly transport antigen from the airways to the thoracic lymph nodes. J Exp Med, 193(1), 51-60.

Vermaelen, K. Y., Cataldo, D., Tournoy, K., Maes, T., Dhulst, A., Louis, R., . . Pauwels, R. (2003). Matrix metalloproteinase-9-mediated dendritic cell recruitment into the airways is a critical step in a mouse model of asthma. J Immunol, 171(2), 10161022.

Wilson, N. S., El-Sukkari, D., \& Villadangos, J. A. (2004). Dendritic cells constitutively present self antigens in their immature state in vivo and regulate antigen presentation by controlling the rates of MHC class II synthesis and endocytosis. Blood, 103(6), 2187-2195. 
Zeng, X., Wert, S.E., Federici, R., Peters, K.G. \& Whitsett, J.A. (1998). VEGF enhances pulmonary vasculogenesis and disrupts lung morphogenesis in vivo. Dev Dyn, 211, 215-227. 


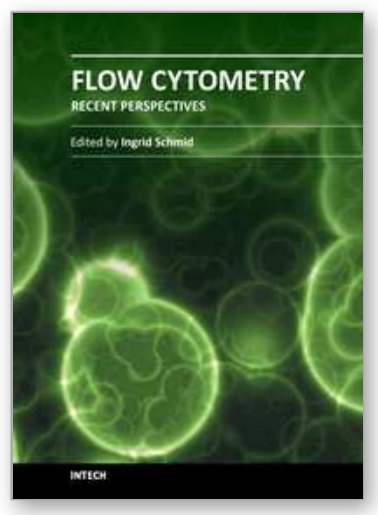

\section{Flow Cytometry - Recent Perspectives}

Edited by M.Sc. Ingrid Schmid

ISBN 978-953-51-0626-5

Hard cover, 500 pages

Publisher InTech

Published online 13, June, 2012

Published in print edition June, 2012

"Flow Cytometry - Recent Perspectives" is a compendium of comprehensive reviews and original scientific papers. The contents illustrate the constantly evolving application of flow cytometry to a multitude of scientific fields and technologies as well as its broad use as demonstrated by the international composition of the contributing author group. The book focuses on the utilization of the technology in basic sciences and covers such diverse areas as marine and plant biology, microbiology, immunology, and biotechnology. It is hoped that it will give novices a valuable introduction to the field, but will also provide experienced flow cytometrists with novel insights and a better understanding of the subject.

\section{How to reference}

In order to correctly reference this scholarly work, feel free to copy and paste the following:

Svetlana P. Chapoval (2012). Flow Cytometry-Based Analysis and Sorting of Lung Dendritic Cells, Flow Cytometry - Recent Perspectives, M.Sc. Ingrid Schmid (Ed.), ISBN: 978-953-51-0626-5, InTech, Available from: http://www.intechopen.com/books/flow-cytometry-recent-perspectives/flow-cytometry-based-analysisand-sorting-of-lung-dendritic-cells

\section{INTECH}

open science | open minds

\section{InTech Europe}

University Campus STeP Ri

Slavka Krautzeka 83/A

51000 Rijeka, Croatia

Phone: +385 (51) 770447

Fax: +385 (51) 686166

www.intechopen.com

\section{InTech China}

Unit 405, Office Block, Hotel Equatorial Shanghai

No.65, Yan An Road (West), Shanghai, 200040, China 中国上海市延安西路65号上海国际贵都大饭店办公楼 405 单元

Phone: $+86-21-62489820$

Fax: +86-21-62489821 
(C) 2012 The Author(s). Licensee IntechOpen. This is an open access article distributed under the terms of the Creative Commons Attribution 3.0 License, which permits unrestricted use, distribution, and reproduction in any medium, provided the original work is properly cited. 